\title{
A response to the commentary entitled: "Addressing the shortage of health professionals in rural China: issues and progress"
}

\author{
Qian Yang, Hengjin Dong*
}

\author{
*Correspondence to: Hengjin Dong, Email: donghj@zju.edu.cn \\ Copyright: () 2015 by Kerman University of Medical Sciences \\ Citation: Yang Q, Dong H. A response to the commentary entitled: "Addressing the \\ shortage of health professionals in rural China: issues and progress". Int J Health Policy \\ Manag 2015; 4: 329-330. doi: 10.15171/ijhpm.2015.83 \\ Received: 29 March 2015, Accepted: 12 April 2015, ePublished: 14 April 2015
}

$\mathrm{T}$ The principal problems of healthcare services in China are "difficulty in seeing a doctor" and "high expense of getting medical service" (commonly known in Chinese as "kan bing nan, kan bing gui"). The central Chinese government has already launched the bottom-up cascading medical system and two-way referral system recently in order to solve these problems (1). Only when patients go to medical institutions in an orderly fashion, can we see the hope of breaking the kan bing nan, kan bing gui (2). However, we face a number of obstacles when implementing the referral policies. The biggest obstacle is the lack of Human Resource (HR) for primary care both in capacity and volume (3). The central Chinese government has launched a series of policies to deal with the shortage of HRs in rural areas. Profound measurements involve postgraduate training for General Practitioner (GP) (a three-year plan beginning in 2010 for producing health professionals for rural areas and improving rural retention), " $3+2$ " medical education model (3-year diploma education and 2-year postgraduate GP training), and in-service training for physicians in rural areas (4). It is not the time to assess their effectiveness, however, these measurements are certain to improve the capacity of Community Health Service (CHS) institutions.

But, the above measurements mainly focus on the capacity building, not on the quantity of HRs in rural areas. In addition, CHS institutions still face many problems to attract the welltrained GPs. These problems will damage the effects of the above policies, and even aggravate the mal-distribution gap in HRs between urban and rural areas. The willingness of physicians to flow from urban to rural areas are affected by lots of factors including financial incentives, career development, and living conditions (5-8). The reality is that GP residency training programs cannot attract enough students due to GP's low salary, social status and limited career opportunities (9). In terms of the financial incentives, the salary of a GP in a rural area is half of a physician in secondary hospitals, or even less (10). Moreover, the new polices have paid little attention to determinants of career development and living conditions. To make the policy more attractive by economic stimuli, the central government issued a compensation policy that each student will get 6,000 Yuan (about 950 US dollars) a year for choosing the GP education for rural area. However, the central government only offered this financial aids in Western and Central China $(11,12)$. As we know, most of the inequality accounted for by within-province rather than betweenprovince inequalities (13). So, the rural areas in eastern provinces of China also need such financial incentives.

As far as career development is concerned, the career development system is independent of each other between CHS institutions and Big Hospitals. This system design has eliminated the possibility of transfer through development for all GPs. If a medical student decided to go to the CHS center or village health station after the GP education, there is little chance for him/her to transfer to a hospital in the city. Moreover, " $3+2$ " medical education model has faced the poor execution that all students who have finished the 2-year GP education to work in rural areas. Although there is a request for them to work for CHS entities for six years $(11,12)$, there appears a lack of compulsory guaranteesfor their retention. Students take free education for GP training, and they are also free to leave the CHS Institution. Most of the students could choose secondary or tertiary hospitals where they are accepting the GP education freely instead of returning to the $\mathrm{CHS}$ center or village health station as they promised. Even though the CHS institution paid their salaries for years, it is hard for the institution to retrieve these investments. Some students have breached the contract and awarded damages to the government, others have chosen additional two-year education to become a physician.

These will lead to failure of the policy. The most significant personnel status in rural areas is still the temporary shortage, not just the quantity of the GPs. The shortage exists before and also after the implementation of the policies. There are not enough trained younger men and women ready to take over from older GPs (14). The severe lack of HRs in rural areas results in the breakup of village health stations. Because in many areas, there is only one GP in the village health station. After he or she dies, there will be no successor to continue his or her business.

In these grim situations, Chinese government should take measurements to attract more well-trained GPs to work in CHS institutions, and to retain students who completed the 2-year postgraduate GP training to return to rural areas as they promised. For instance, we can enhance the salary level of GPs in financial incentive aspect, or include the CHS institutions under the umbrella of secondary hospitals to make more career promotion opportunities for the GP, or set up GP associations to provide social and technique support to GPs, and improve their social status. Corresponding policy 
suggestions also involve taking short-term measurements of the shortage of GPs in rural areas. On the one side, the local medical school should get the permission to train some GPs who can assume the necessary medical work in village stations, more importantly, who are willing to stay in rural areas; on the other side, the in-service training in local areas should be enhanced.

Ethical issues

Not applicable.

\section{Competing interests}

Authors declare that they have no competing interests.

Authors' contributions

HD and QY conceptualized the letter. QY drafted the manuscript. HD and QY finalised and approved the manuscript.

\section{References}

1. Wang L, Dong $\mathrm{H}$, Yang $\mathrm{Q}$, Gao L, Zhen X. Policy support mechanism of hierarchical treatment reform in Zhejiang provine. In: College ZM, editor. Academic Symposium about Primary Health Care Reform of Eastern China. Hangzhou: Zhejiang Medical College; 2014. p. 253-8.

2. Dong H, Ma W, Wang Z, Shentu Z, Xu F. Status and Progress of Bottom-up cascading medical system in Zhejiang Province. In: College ZM, editor. Symposium about Primary Health Care Reform of Eastern China. Hangzhou: Zhejiang Medical College; 2014. p. 320-6.

3. Yang Q. Problem and Stragegy for First Contract in Primary Care: A Psychological study based on primary health care human resources. In: College ZM, editor. Academic Symposium about Primary Health Care Reform of Eastern China. Hangzhou: Zhejiang Medical College; 2014. p. 308-19.

4. Hou J, Ke Y. Addressing the shortage of health professionals in rural China: issues and progress. Int $\mathrm{J}$ Health Policy Manag 2015; 4: 327-8. doi: 10.15171/ijhpm.2015.57

5. Dong X, Proochista A, Xiao X. An investigation of Chinese rural doctors'job quit intention: empirical analysis of income satisfaction, hospital organization satisfaction and doctor-patient relationship. Economic Review 2013: 30-9. [in Chinese]

6. Ren S, Liu L, Jiang Q. An analysis of current situation and problems on Chinese rural health human resources. Chinese Health Services Management 2013; 12: 912-4. [in Chinese]

7. Long S. Rural grass-root health professionals in China: current situation, influential factors, and suggestions. J Med Theo Prac 2013; 7: 878-9. [in Chinese]

8. Wei Y, Duan Q, Bao G. Analysis on the current status and issues of rural health workforce in Jiangsu province. Modern Preventive Medicine 2015; 42: 269-72. [in Chinese]

9. Kong X, Yang Y. The current status and challenges of community general practitioner system building in China. QJM 2014; 108: 89-91. doi: 10.1093/qjmed/hcu222

10. Woodhead M. How much does the average Chinese doctor earn? 2014 [updated 31 March, 2014]. [cited 20157 April]. Available from: http://www.chinesemedicalnews.com/2014/03/ how-much-does-average-chinese-doctor.html

11. Ministry of Health of China, National Development and Reform Commission of China, Ministry of Education of China. Plan on Building Grass-root Health Workforce that Focusing on General Practitioners; 2010.

12. The State Council of China. Suggestions on Establishing the GP System; 2011.

13. Anand S, Fan VY, Zhang J, Zhang L, Ke Y, Dong Z, et al. China's human resources for health: quantity, quality, and distribution. Lancet 2008; 372: 1774-81. doi: 10.1016/S01406736(08)61363-X

14. He P, Wang $H$. The cost-effectiveness analysis and thought for "village physicians" project in Wujin area. Chinese Rural Health Service Administration 2014; 34: 819-21. 